\title{
Dissipation Kinetics of Tebuconazole Residues in Grape
}

\author{
Sofiana Mai, Ederina Ninga, Mimoza Mukaj, Anisa Liti, and Magdalena Cara
}

\begin{abstract}
Tebuconazole residues were determined on grapes treated with minimal and maximal recommended concentrations. The grapes samples were collected randomly after 1, 5, 10, 15 days after last application, extracted using the ethyl acetate method, and finally analyzed with a gas chromatograph instrument. The method was validated, and performance criteria complied with legislation requirements. Recovery data was over $90 \%$, the limit of quantification Limit of Quantification was smaller than maximum residue limit and linearity $\leq \mathbf{2 0} \%$. According to the maximum residue limit, the degradation of Tebuconazole for the recommended concentrations applied dissipated between 10 and 15 after the last treatment.
\end{abstract}

Index Terms-Tebuconazole Residues; Dissipation Kinetics; Maximum Residue Limit.

\section{INTRODUCTION}

Grape production is an important activity because grapes are commonly consumed, both as fresh and as processed food, as well as grapes have high nutritional properties [1]. The grape crop is frequently infested by several diseases at all stages of its development. The crop is often applied with chemical pesticides to offer protection from severe damage [2]. Diseases in grape vineyards caused by microorganism pathogens are called parasitic diseases, while those caused by factors such as inappropriate land, food, water regime in the earth, climate conditions etc., are called physiological diseases [3]. The dissipation of the pesticides after their application depends on several factors, such as the applied dose and formulation, application parameters, the number of applications, climatic conditions, the species cultivated, physical phenomena, and chemical degradation [4]. The impact of pesticides and other toxic chemicals on the environment depends on the interaction with soil particles. It is important to know whether released residues are of toxicological and/or ecological significance [5]. The development of export markets of fresh grape is hindered by concerns regarding pesticide residues and inadequate monitoring programs [6].

Tebuconazole is a triazole fungicide used as a seed dressing and spray. Regarding to FRAC (Fungicide Resistance Action Committee) this group known as DeMethylation Inhibitors (DMI-fungicide) in sterol biosynthesis. According to the World Health Organization toxicity classification, it is listed in class III, which means slightly hazardous.

Published on October 15, 2018.

S. Mai, E. Ninga, M. Mukaj and M. Cara are with the Faculty of Agriculture and Environment, Agricultural University of Tirana, Albania. (e-mail: sofiana.mai@gmail.com)

A. Liti is with the Applied and Natural Sciences Department, Professional Studies Faculty, Aleksandër Moisiu University, Durrës, Albania.

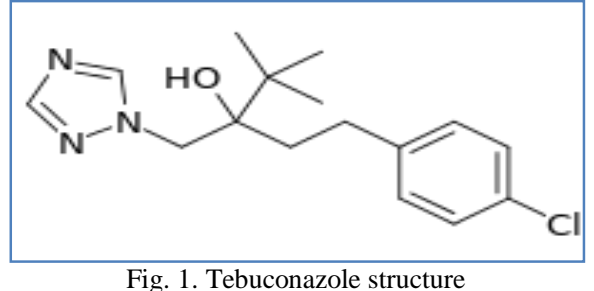

The present investigation aims to determine the residue levels of the Tebuconazole fungicide in grapes when two recommended doses are applied. Also, the study aims to detect the pre-harvest intervals (PHI) for the mentioned pesticide to avoid health risks.

\section{MATERIAL AND METHOD}

\section{A. Field experiment and samples collection}

Tebuconazole is the ISO common name for (RS)-1-pchlorophenyl-4, 4-dimethyl-3-(1H-1,2,4-triazol1-ylmethyl)pentan-3-ol (IUPAC). Tebuconazole is a systemic fungicide belonging to the class of triazoles. The compound acts as an ergo sterol biosynthesis inhibitor [7]. The experiment was conducted in a grape vineyard/farm in Maminas, Durres. The field site has been cultivated with grapes for the last five years. Two treatments (variants) of maximum and minimum dosage, as defined in the Tebuconazole product label, were applied. Each treatment (variant) was performed on 15 grape plants, while 15 other grape roots were not treated to be used as control sample. The samples were collected 1, 5, 10, 15 after last treatment regarding to 2002/63/EC [8]. The pesticide was applied using a manually operated pump, and the treatment of vineyard was carried by a trained person, who used all personal protective equipment during the application of the pesticide. Approximately $1 \mathrm{~kg}$ for each grape sample was transferred to the laboratory immediately.

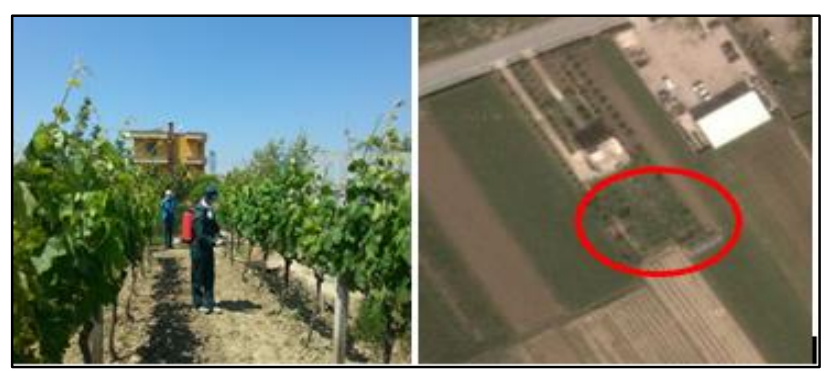

Fig. 2. Map of sampling location and aspects of application process by a trained person

The analysis of tebuconazole residues were performed in Pesticides Residues Laboratory in Food Safety and Veterinary Institute. 


\section{B. Sample extraction}

The samples were homogenized using a blender and $10 \mathrm{~g}$ from each sample was weighed in a $50 \mathrm{~mL}$ centrifuge tube and frozen at $-20^{\circ} \mathrm{C}$ until the time of analysis. The samples were extracted according to SweEt method with ethyl acetate, which is an easy, efficient and fast method for pesticide residues [9]. Into the centrifuge tube with $10 \mathrm{~g}$ grape sample $20 \mathrm{~mL}$ ethyl acetate was added. Samples were shaken on a mechanical shaker at $300 \mathrm{rpm} / \mathrm{min}$ for $15 \mathrm{~min}$. Subsequently, $10 \mathrm{~g}$ sodium sulfate was added in each sample. The tubes were shaken again for $10 \mathrm{~min}$ and then centrifuged at $3200 \mathrm{rpm}$ for $3 \mathrm{~min}$. An aliquot of extract was transferred into vials and then injected in gas chromatograph instrument.

\section{Equipment parameters}

The identification and quantification of residues were performed by gas chromatography coupled with tandem mass spectrometry (Agilent technologies 7890A) in multiple reaction monitoring (MRM) in EI MS/MS mode. The injection volume was $1 \mu \mathrm{L}$. The column used for pesticide residues separation with a column HP-5 MS (30 m x 250 $\mu \mathrm{m} \times 0.2 \mu \mathrm{m})$. Mass spectrometer was operating in Electron Impact Ionization (EI) mode. The electron energy was 70 $\mathrm{eV}$ and the temperature source at $290^{\circ} \mathrm{C}$. The initial oven condition started at $50^{\circ} \mathrm{C}$ for 0,6 minute following by a temperature increase up to $180^{\circ} \mathrm{C}$ at a rate of $15^{\circ} \mathrm{C} / \mathrm{min}$ held for one minute. Then the temperature was increased at $230^{\circ} \mathrm{C}$ by $7^{\circ} \mathrm{C} / \mathrm{min}$ and the last step was up to $280^{\circ} \mathrm{C}$ by $3^{\circ} \mathrm{C} / \mathrm{min}$.

\section{Chemicals and reagents}

The analytical standard of Tebuconazole was purchased by Bayer Crop Science AG (99.1\% purity) and its standard stock solution was prepared in ethyl acetate and stored in dark below $4^{\circ} \mathrm{C}$.Reagent such as sodium sulphate anhydrous and ethyl acetate were purchased from VWR International. Commercial formulations of Tebuconazole (Alien 250g/L) were provided by SIPCAM.

\section{RESULTS AND DISCUSSION}

\section{A. Method evaluation}

The method for determination of tebuconazole residues was validated by following the parameters listed on guidance document on residue analytical methods [10]. The checked parameters are linearity, recovery, limit of detection (LOD) and limit of quantification (LOQ). A six-point calibration curve in solvent and another curve in matrix were constructed. Linearity evaluated in matrix, using matrix-matched calibration curves $\left(\mathrm{R}^{2}=0.98\right)$ and calibration curve of solvent $\left(\mathrm{R}^{2}=0.99\right)$ was fulfilled per validation parameters.
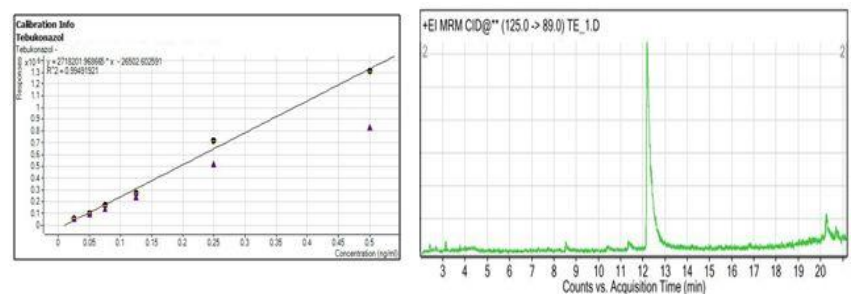

Fig. 3. Calibration curve of Tebuconazole and a sample grape chromatograme

Limit if quantification $(\mathrm{LOQ}=0.07)$ was lower than MRL of tebuconazole in grape. For recoveries analysis, the control plot was used as blank sample and the results are shown in table below.

TABLE I: RECOVERIES RESULTS OF METHOD VALIDATION OF TEBUCONAZOLE IN GRAPE

\begin{tabular}{ccccc}
\hline \hline $\begin{array}{c}\text { Spike } \\
\text { levelsmg/kg }\end{array}$ & $\begin{array}{c}\text { Recovery } \\
\%\end{array}$ & $\begin{array}{c}\text { RSD }_{\mathrm{r}} \\
\%\end{array}$ & Sanco & $\begin{array}{c}\text { Horwitz } \\
\%\end{array}$ \\
\hline 0.1 & 93 & 7 & $\mathrm{RSD} \leq 20 \%$ & 23 \\
0.25 & 94 & 4 & $\mathrm{RSD} \leq 20 \%$ & 20 \\
0.5 & 111 & 4 & $\mathrm{RSD} \leq 20 \%$ & 18 \\
\hline \hline
\end{tabular}

The evaluations of the influence of matrix components (ME) on chromatographic response were performed using the slope of the matrix match calibration curve and the slope of calibration curve in solvent. ME (\%) in this case exceed the value of $100 \%$ and had strong matrix effect.

\section{B. Dissipation of tebuconazole}

Dissipation behavior of tebuconazole followed the firstorder kinetic with a moderately correlation coefficient $\left(\mathrm{R}^{2}=0.903\right)$.

The initial deposits of tebuconazole for maximum dose of treatment were $1.29 \mathrm{mg} / \mathrm{kg}$ and then after 5 days were dissipated to $1.1 \mathrm{mg} / \mathrm{kg}$.

$$
\begin{aligned}
& \text { First order kinetic: } \\
& \text { Half-time: }
\end{aligned} \quad \begin{aligned}
\mathrm{C}=\mathrm{C}_{0} \mathrm{e}^{-\mathrm{kt}} \\
\mathrm{t}_{1 / 2}=\ln 2 / k
\end{aligned}
$$

where:

$\mathrm{C}_{0}=$ initial deposits after treatment

$\mathrm{K}=$ rate of degradation

TABLE II: REGRESSION EQUATION, CORRELATION COEFFICIENT AND HALF-TIME OF TEBUCONAZOLE IN GRAPE

\begin{tabular}{ccc}
\hline \hline $\begin{array}{c}\text { Regression } \\
\text { equation }\end{array}$ & $\begin{array}{c}\text { Correlation coefficient } \\
\left(\mathrm{R}^{2}\right)\end{array}$ & $\begin{array}{c}\text { Half-life } \\
(\text { days })\end{array}$ \\
\hline $\mathrm{Y}=2.024 \mathrm{e}^{-0.13 \mathrm{x}}$ & 0.903 & 5.331 \\
$\mathrm{Y}=0.755 \mathrm{e}^{-0.04 \mathrm{x}}$ & 0.962 & 17.35 \\
\hline \hline
\end{tabular}

The Table II shows the calculated values of degradation constant, coefficient of determination $\left(\mathrm{R}^{2}\right)$ for the first order dissipation kinetics and half-lives of tebuconazole under field conditions at two different treatment levels. Complete dissipation of residues occurs between 10 and 15 days after the last treatment. Calculations are done in accordance to Single First-Order Rate Model. The single first-order kinetics model (SFO) specifies that the rate of concentration decline is proportional to the concentration in the system [11]. The half-life calculated for the double dose of treatment was 5.33 days and for the lowest treatment was more than 5 days recommended. 


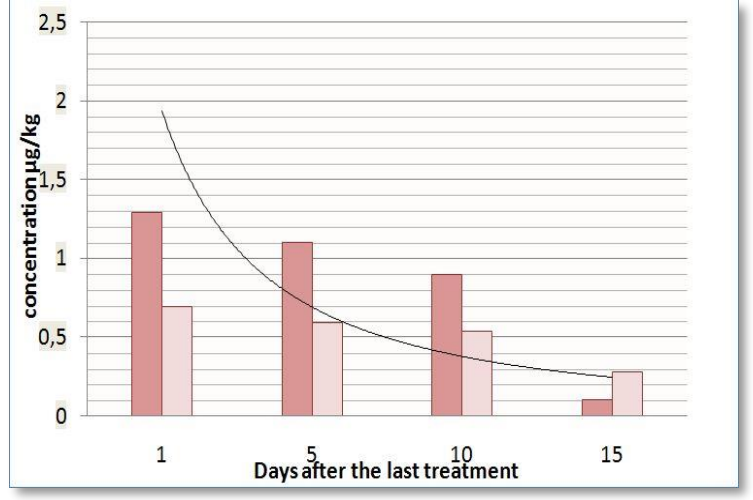

Fig. 4. Tebuconazole residues from the first till $15^{\text {th }}$ days after last treatment in grape

The residues of tebuconazole were all below the maximum residue limits, while the MRL is $0.5 \mathrm{mg} / \mathrm{kg}$. As PHI (pre-harvest intervals) is that time of harvest when no residue exists above MRL, the values are under $0.5 \mathrm{mg} / \mathrm{kg}$ and the persistence of tebuconazole residues decreased from $100 \%-7.7 \%$ from $1^{\text {st }}$ day to $15^{\text {th }}$ after treatment for residues levels of maximum recommended dose. The tendency is in full degradation of tebuconazole and sample grape can be harvest at day 15 after treatment, because the residues level are below maximum allowed levels.

\section{CONCLUSION}

Residues of tebuconazole were successfully extracted by SweEt method. The obtained results are within acceptable validation criteria for pesticide residue analysis according SANTE/11945/2015. The present results suggested that it is safe to harvest tebuconazole treated grapes 15 days after last recommended treatment. The study above estimates the residues level of tebuconazole in grape and risk assessment till the pre-harvest day of this commodity. We will recommend other studies to evaluate the risk for pesticide residues of different commodities in our country to protect the consumer from exposure of pesticides.

\section{ACKNOWLEDGMENT}

Authors thank for the support of this study the pesticide residues laboratory of Food Safety and Veterinary Institute, Department of Toxicology, Tirana, Albania

\section{REFERENCES}

[1] Ioan S., M. M. (2011). Determination of the organochlorine pesticide residues contents in grapes by sbse-td-gc-ecd analysis. Studiaubbchemia, lxi, 3, tom ii, 432.

[2] Hassan E., A. N. (2013). Dissipation and Residues of Lufenuron in Grape Fruits. American Journal of Environmental Protection, pp. 1719 doi:10.12691/env-1-2-1.

[3] Isufi E., S. V. (2005). Good agricultural practices for sustainable production of grapes. Tirane, albania.

[4] Malhat F. M., M. A. (2012, February 2). Dissipation and Residues of Mandipropamid in Grape Using quechers Methodology and HPLC$D A D$. ISRN Analytical Chemistry, p. 5.

[5] Mukaj M., M. S. (2016). Determination of Persistent Organic Pollutants in Soils of some Greenhouses in Albania, The International Scientific Multi-Conference ATTENTIS 2016, Procedia Agricultural Science.

[6] M. R. Montasser, m. H. (2009). Chromatographic Determination of Azoxystrobin, Fenhexamid and Lufenur on Residues in Grapevin. Alexandria science exchange journal, vol.30, no.1 january-march, 3743.

[7] EFSA. (2015). Modification of the existing mrls of tebuconazole in cucumbers and courgettes. Efsa journal, ;13(1):4000, pp. 1-24.

[8] Commission Directive 2002/63/EC. (11 July 2002). Commission Directive 2002/63/EC establishing Community methods of sampling for the official control of pesticide residues in and on products of plant and animal origin and repealing Directive 79/700/EEC.

[9] NCFA, N. C. (2013). Pesticide residues level in foods with ethyl acetate extraction using gas and liquid chromatography with tandem mass spectrometric determination.

[10] SANTE/11945/2015. (2015). Guidance document on analytical quality control and validation procedures for pesticide residues analysis in food and feed.

[11] NAFTA. (n.d.). Https://www.epa.gov/sites/production/files/201509/documents/degradation-kin.pdf. 